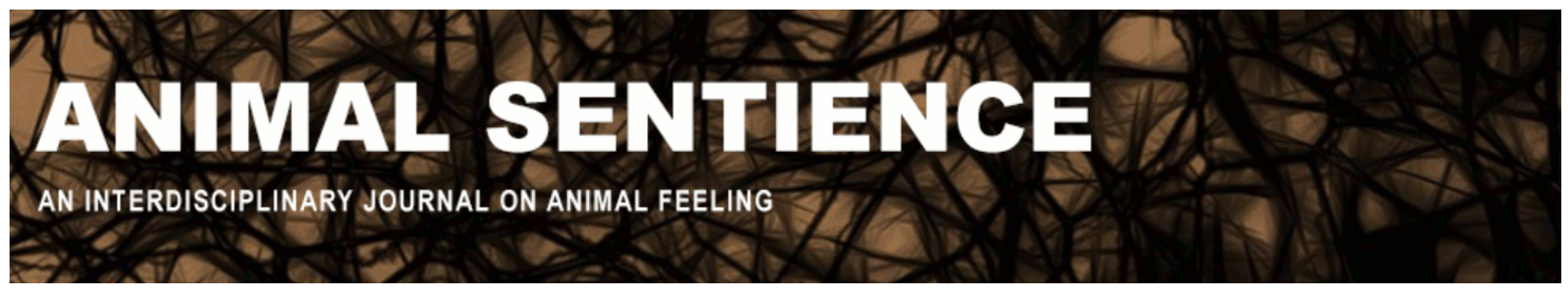

Thomas, Roger K. (2017) Is psychological science committing "suicide" by linguistic muddling?. Animal Sentience 20(8)

DOI: 10.51291/2377-7478.1295

Date of submission: 2018-01-11

Date of acceptance: 2018-01-15

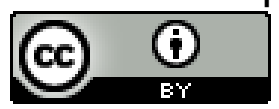

This article has appeared in the journal Animal

Sentience, a peer-reviewed journal on animal

cognition and feeling. It has been made open access,

free for all, by WellBeing International and deposited

in the WBI Studies Repository. For more information,

please contact

wbisr-info@wellbeingintl.org.

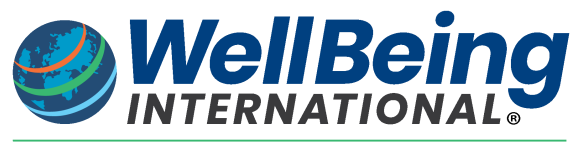

SOLUTIONS FOR PEOPLE, ANIMALS AND ENVIRONMENT 


\title{
Is psychological science committing "suicide" by linguistic muddling?
}

\author{
Commentary on Peña-Guzmán on Animal Suicide
}

\author{
Roger K. Thomas \\ Department of Psychology \\ University of Georgia
}

\begin{abstract}
Beginning mainly with the "cognitive revolution" in psychology in the latter half of the $20^{\text {th }}$ century, psychological science has been committing "suicide" slowly via linguistic muddling. Peña-Guzmán's target article is but one of thousands of cuts contributing to this death by "suicide." Having said that, given the current state of affairs in animal cognition research, there is much to commend in Peña-Guzmán's article. I leave that to others, however. This commentary explains how the suicide by muddling of psychological science is happening in general, with the understanding that it applies also to Peña-Guzmán's target article.
\end{abstract}

Roger K. Thomas, Professor Emeritus, earned B.S., M.S., and Ph.D. degrees at the University of Georgia and held a two-year postdoctoral fellowship in neurobiological sciences at the University of Florida College of Medicine. He is aware that when he is not present, some of his young colleagues refer to him as "old school." If trying one's best to reason and use language carefully is "old school," then he wears that label

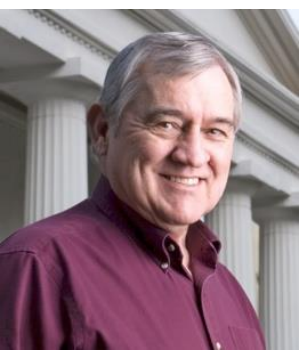
proudly. faculty.franklin.uga.edu/rkthomas/

Background. For a discussion of the mythical cognitive revolution in American psychology, see Leahey (1992). For a discussion of linguistic muddling, see Bateson (1972/2000; especially his Introduction and Part I: Metalogues). For a discussion of the false Idols that obstruct clear thinking and, hence, result in muddling, see Bacon's Novum organum (1620/1911). In Bacon's “Idols of the Marketplace," he warned against the fallibilities of language and explained how they are a barrier to clear thinking.

How linguistic muddling happens. For 30 years, I taught "Neuroanatomy for Behavioral Scientists" at the graduate level, mostly but not always alternating textbooks between the most current editions of Alf Brodal's (or his successor's) Neurological anatomy or Malcolm B. Carpenter's (who sometimes had coauthors and eventually a successor) Human neuroanatomy. From this experience and many additional resources, I have concluded that all central nervous system (CNS) processing reduces to three fundamental and continually interacting categories: sensory processing, effector (some might prefer "motor") processing, and memory processing. Associated with each are physicochemical changes in the CNS, where the changes at one instant in time may interact and alter changes in the next instant of time. 
There are no isomorphic CNS physicochemical substrates for any of the concepts used by psychological scientists or, in Peña-Guzmán's case, philosophers. Concepts such as "suicide," "intelligence," "creativity," "love," "hate," fear," "anxiety," "stress," ad nauseam are merely fictional tag-alongs borrowed from folk psychology or common language - or invented to avoid the tedious and never-ending task of identifying the relevant external antecedent and consequent events that must be observed to infer their potential explanatory usefulness and to define them. Antecedents and consequents might also be observed internally in the CNS via electrical, chemical, and other manipulations using methods such as stimulation, ablation, and recording. About neural activity monitoring such as functional MRI's, magnetoencephalography, etcetera to identify brain functions, I am inclined to agree with Uttal (2003) who referred to such findings as "The new phrenology." In his more recent book, Uttal (2012) made an even stronger case

Any definition of such tag-along concepts (see list above) is inherently incomplete. Because such concepts have no specific physicochemical substrates, they are fictitious; that is, they are not materially real; and that is where muddling arises. Many "cognitive" concepts are reified by their users; they are often misused as representing, for example, causes or effects. For a specific example, one can cite articles in respected academic journals where researchers used "stress" variously as both a cause and an effect associated with one observable behavior or another.

An animal cannot commit "suicide" because "suicide" exists as an inherently and incompletely defined concept. At the very least, when one uses a "cognitive" concept for any purpose, one should acknowledge its inherent limitations and let that be the guide to how one should use it.

A diagrammatic representation of the general argument here appears below (Figure 1). Similar diagrams might be constructed for any "cognitive" concept used by philosophers or psychological scientists.

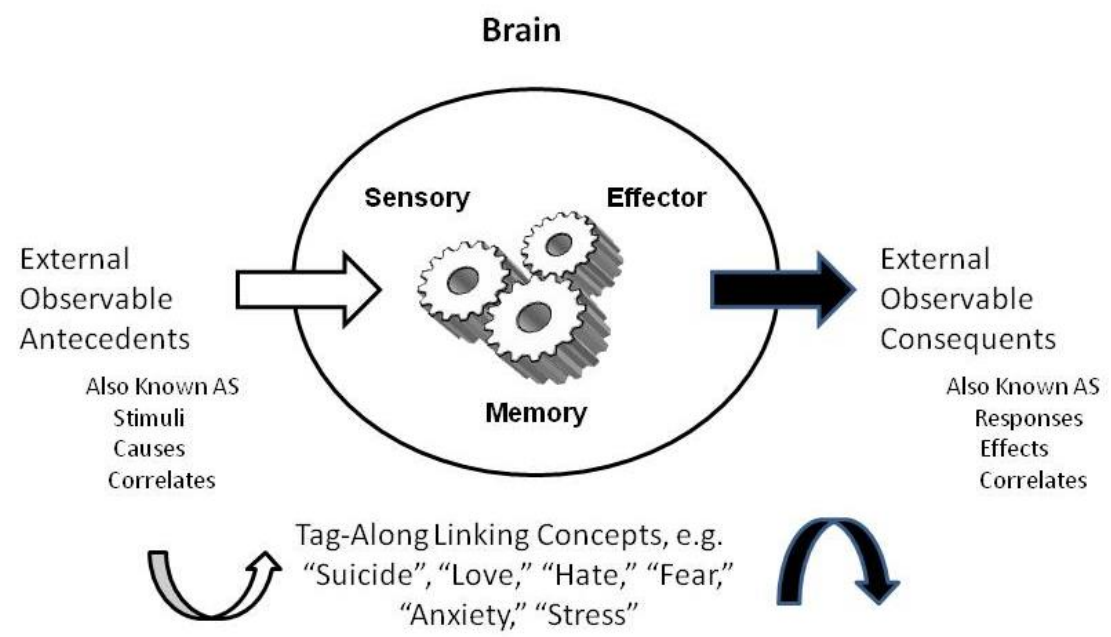

Figure 1. A representation of the brain and its three fundamental, material-based sensory (open arrow), memory, and effector (filled arrow) processes. These processes are affected by material antecedent events, and they interact to determine material consequent events. The tag-along linking concepts used to describe such events are fictional (i.e., immaterial) adaptations from common language or inventions that are definable only in reference to the aforementioned material processes. 


\section{References}

Bacon, F. (1620/1911). Novum organum. New York, NY: P. F. Collier \& Son.

Bateson, G. (1972/2000). Steps to an ecology of mind. Chicago, IL: The University of Chicago Press.

Leahey, T. H. (1992). The mythical revolutions of American psychology. American Psychologist, 47(2), 308-318.

Peña-Guzmán, D. M. (2018). Can nonhuman animals commit suicide? Animal Sentience 20(1).

Thomas, R. K. (2016). Brain and intelligence. In H. L. Miller (Ed.). Encyclopedia of theory in psychology (pp. 106-110). Thousand Oaks, CA : SAGE Publications Inc.

Uttal, W. R. (2003). The new phrenology: The limits of localizing cognitive processing in the brain. Cambridge, MA: MIT Press.

Uttal, W. R. (2012). Reliability in cognitive neuroscience: A meta-meta analysis. Cambridge, MA: MIT Press. 